\title{
Small mammal (Mammalia, orders Soricomorpha and Rodentia) communities in the lower Black river basin, Romania
}

\author{
Anamaria Lazăr ${ }^{1}$, Ana Maria Benedek² \\ 1 "Transilvania" University of Braşov, Faculty of Food and Tourism, Department for Engineering and \\ Management in Food and Tourism, 148 Castelului street, 500036 Braşov, Romania \\ 2 "Lucian Blaga" University of Sibiu, Faculty of Science, Department of Enviromental Sciences, \\ Physics, and Sport Education, 5-7 Ion Raţiu street, 550012 Sibiu, Romania \\ Corresponding author: Anamaria Lazăr (anagurzau@yahoo.co.uk)
}

Received 7 November 2018 | Accepted 6 May 2019 | Published 31 July 2019

Citation: Lazăr A, Benedek A-M (2019) Small mammal (Mammalia, orders Soricomorpha and Rodentia) communities in the lower Black river basin, Romania. Travaux du Muséum National d'Histoire Naturelle "Grigore Antipa” 62(1): 125-135. https://doi.org/10.3897/travaux.62.e38592

\begin{abstract}
The survey of small mammal communities in the Lower Black River Basin was carried out between November 2005 and July 2012 in three locations. Using live traps several habitats have been investigated. During the study, we captured 199 individuals belonging to 9 species -2 shrews and 7 rodents. Four other species were identified based on direct or indirect observations.
\end{abstract}

\section{Keywords}

rodents, shrews, community structure, live trapping, Lower Black River Basin.

\section{Introduction}

The study in the Lower Black River Basin took place in three locations: Ozun, Dobârlău, and Lisnău Vale. In Ozun, we carried out an intensive study between November 2005 and July 2012, aiming to reveal the habitat use and structure of small mammal communities. In Dobârlău and Lisnău Vale we conducted an extensive study, investigating the diversity of small mammals in different habitats situated near these localities. 
There has been little research conducted on small mammals in the Lower Black River Basin; the only available data were published by L. Molnár (1980-1981), the study being based on the analysis of Asio otus (Linnaeus, 1758) pellets collected from Sfântu Gheorge town and Mestecănişul de la Reci Natural Reserve, between 1978 and 1980. The author identified 12 small mammal species belonging to the Rodentia and Soricomorpha orders.

\section{Study Area and Methods}

The Ozun locality is situated in the Câmpu Frumos Depression, which is part of the Brașov Depression. Its easternmost part is mountaineous, situated at the base of the Vrancea Mountains, and it merges with the Lisnău Valley. Its central-northern part is in the vicinity of Reci, a reservation of birch and oligotrophic marshes. The central-southern part is the lowest part of Depression. Ozun locality is situated at an average altitude of $515 \mathrm{~m}$ and is crossed along its entire length by the Black River. On this territory there are some lakes resulting from the regularization of this river.

The multi-annual average temperature recorded at Sfântu Gheorghe is $7.6^{\circ} \mathrm{C}$, and atmospheric precipitations that fall is around $500-700 \mathrm{~mm} /$ year (Stanca and Raduly 1980).

In Ozun locality, at $511 \mathrm{~m}$ altitude, at $45^{\circ} 48^{\prime} 17^{\prime \prime} \mathrm{N}$ and $25^{\circ} 51^{\prime} 20^{\prime \prime} \mathrm{E}$, we investigated five habitats between November 2005 and July 2012.

The first habitat was the cemetery, a habitat consisting of lilac thicket (Syringa vulgaris L.) and a meadow; a transect of traps was installed on the bank of the Black River in a riparian forest consisting of white wilows (Salix alba L.), with stinging nettles (Urtica dioica L.), dewberry (Rubus caesius L.), and common comfrey (Symphythum officinale L.); other traps have been installed on a farm land that has been sowed with different crop plants; the fourth habitat was the church courtyard, and the fifth habitat was a permanent alfalfa field.

In each of the mentioned habitats we installed monthly a variable number of traps, on average ten. Except for the cemetery, where traps were installed randomly, the other traps were installed in transects.

Dobârlău locality is situated in the valley of the Dobârlău stream, in the western part of the Buzău Mountains, at an altitude of $540 \mathrm{~m}$. Between April $29^{\text {th }}$ and May $1^{\text {st }}, 2006$, we carried out a field campaign in this locality. We installed 36 traps at an altitude of $561 \mathrm{~m}$, at $45^{\circ} 44^{\prime} 06^{\prime \prime} \mathrm{N}$ and $25^{\circ} 53^{\prime} 00^{\prime \prime}$ E. Among these, 22 were installed in a $2 \times 11$ grid in a pine forest and 14 traps were randomly installed in the open field at the forest edge. The weather during this period was stable without precipitation and without wind.

Lisnău Vale is located at an altitude of $550 \mathrm{~m}$ on the Lisnău River valley.

In 2010 and 2011, we conducted live trapping in different types of habitats near the locality. The first investigated habitat was a wooded pasture located at $609 \mathrm{~m}$ altitude, at $45^{\circ} 46^{\prime} 02^{\prime \prime} \mathrm{N}$ and $25^{\circ} 55^{\prime} 38^{\prime \prime} \mathrm{E}$. The trees were approximately $10-20$ years old 
(approximation by tree thickness and information received from locals). Birch (Betula pendula Roth), Norway spruce (Picea abies (L.) Karsten), beech (Fagus sylvatica L.), and hornbeam (Carpinus betulus L.) were the prevalent species. This habitat is subject to great anthropogenic pressure, being the main source of firewood for the locals, as well as a place frequented by sheep and cows of the village. The second studied habitat was a spruce forest. These habitats were investigated three nights per month, in October, November, and December 2010. The last habitat, investigated for 30 nights in March 2011, was a grazing glade. In all habitats we used 30 traps per night. During this time, no mammal was captured.

Small mammals were trapped using hand-crafted box-traps made of wire mesh. The traps were installed in line or randomly, the distance between them being on average $10 \mathrm{~m}$. Traps were usually hidden at the base of the trees or in bushes. The traps were provided with food, both to attract animals and to provide them with enough energy until their release, in order to avoid hypothermia. As bait we used different food combinations, both vegetal and animal: bread, pate, peeled sunflower seeds, apple pieces. Traps were also lined with plant material (sawdust or hay) for thermal insulation. The traps were checked twice a day, between $07-09$ and $22-24 \mathrm{~h}$.

Species identification was based on morphological characters, using identification keys and descriptions of Pucek (1981), Görner and Hackenthal (1988), Murariu (2000), Popescu and Murariu (2001), Aulagnier et al. (2009). Marking of animals was done by trimming the fur from the back in different patterns. Marked individuals were released without getting a new tag. A distinction has been made between individuals who have been recaptured in the same campaign and those who have been recaptured from one campaign to another.

Some traps were inoperative for various reasons (being overturned by animals, disturbed or even stolen by humans, closed by rain or wind etc.), so that for the calculation of the capture index we took into account only those traps that were functional.

Relative abundance was expressed as the ratio of the species (in percentages) within a trap-line. Frequency was calculated as the ratio (in percentages) between the trap lines where the species was captured and the total number of trap lines. Abundance, as a measure of population density, was expressed as capture index, meaning the number of captured individuals per 100 active trap-nights (TN) (Sîrbu and Benedek 2012, Sîrbu 2009).

\section{Results and Discussion}

Until now, 19 small mammal species have been identified in the Lower Black River: 7 shrews species belonging to 2 families and 12 rodent species belonging to 4 families. Among them, 12 species were identified in Asio otus pellets from Mestecanisul de la Reci Reserve, 9 were captured in Ozun since November 2005 and 4 have been 
observed in the last few years in the locality. Signs of the presence in the area have been identified for two species.

The systematic list is drawn up in accordance with several recent bibliographic sources: "Mammal species of the world" (Wilson and Reeder 2005) and "Mammals of Europe, North Africa and the Middle East" (Aulagnier et al. 2009).

Order Soricomorpha Gregory, 1910

Family Soricidae Fischer, 1814

1. Sorex araneus Linnaeus, 1758 (Common Shrew) - was encountered around the forest in the Reci area (Molnár 1980-1981) in 1980, representing $0.7 \%$ of the individuals identified in the site. An individual was observed in October 2007 in a yard in Ozun. We captured two individuals on the river bank in Ozun. Its abundance appears to be higher in periods of decline of dominant rodent populations; in two of the study months it was the only species caught on the river bank.

2. Sorex minutus Linnaeus 1766 (Pygmy Shrew) - was found in Asio otus pellets in the Reci Reserve, having greater abundance than S. araneus, representing $2.8 \%$ of the captured animals (Molnár 1980-1981). We captured one individual in the cemetery.

3. Neomys fodiens (Pennant, 1771) (Water Sherw) - one individual was identified in the analysis of pellets collected from Reci (Molnár 1980-1981). It was not identified in the area during this study.

4. Neomys anomalus Cabrera, 1907 (Mediterranean Water Shrew) - was identified in the analysis of pellets collected from Reci (Molnár 1980-1981).

5. Crocidura leucodon (Hermann, 1780) (Bicolored Shrew) - was identified in 1980 in the Asio otus pellets collected from the Reci locality, representing 0.56\% of the prey (Molnár 1980-1981).

6. Crocidura suaveolens (Pallas, 1811) (Lesser White toothed Shrew) - was identified in the same Asio otus pellets but it was less abundant than C. leucodon (0.14\%) (Molnár 1980-1981).

Family Talpidae Fischer, 1814

7. Talpa europaea Linnaeus, 1758 (European Mole) - is very frequent in the area, its presence being signaled by the numerous mole-hills in the area; a few specimens have been found dead in the study areas.

Order Rodentia Bowdich, 1821

Family Sciuridae Fischer de Waldheim, 1817

8. Sciurus vulgaris Linnaeus, 1758 (Eurasian Red Squirrel) - a specimen collected by Ebergènyi from Covasna in 1909 is found in the natural history 
collections of the Sfântu Gheorghe Museum. We observed several individuals in Lisnau Vale, with a higher frequency in the cold season.

Family Castoridae Hemprich, 1820

9. Castor fiber Linnaeus, 1758 (Eurasian Beaver) - it inhabited the Olt River until the beginning of the $19^{\text {th }}$ century, but it became extinct around 1850 (Bielz 1888). At the end of the $20^{\text {th }}$ century, the beaver was reintroduced into the Tuşnad Gorge, from where it expanded downstream. At present, it forms stable populations along the Olt River (Ionescu and Ionescu 2000). Signs of the presence of this species (traces of incisors on tree trunks) have been observed during this study in several places along the Black River since 2011.

Family Cricetidae Fischer, 1817

10. Cricetus cricetus (Linnaeus, 1758) (European Hamster) - several specimens have been observed in different years in the Ozun locality in various agricultural crops, and a skull belonging to a specimen of this species was found in the cemetery.

11. Myodes glareolus (Schreber, 1780) (Bank Vole) - a small number of specimens was found in Reci Reserve, where an individual (representing 0.07\%) was identified in 1979 in the pellets of Asio otus, collected from the forest (Molnár 1980-1981). One specimen was captured for the first time during the 29 field campaigns in June 2012, in the riparian forest on the Black River bank in Ozun. We believe that the species got accidentally into this habitat located at a great distance from the forest, possibly being brought by the flood waters of the previous month.

12. Arvicola amphibius (Linnaeus, 1758) (Eurasian Water Vole) - is quoted from Reci where three individuals were identified, representing $0.13 \%$ of the total number of specimens in the pellets (Molnár 1980-1981). During the present study biometric and parasitological data were collected from four individuals captured in the Lisnau Vale locality in a garden, the presence of the species in the locality being confirmed by the existence of characteristic mounds.

13. Microtus arvalis (Pallas, 1778) (Common Vole) - was mentioned in Reci, being the dominant species in A. otus pellets, representing $87.48 \%$ of the total number of identified vertebrates (Molnár 1980-1981). Throughout the present study, the highest abundance of $M$. arvalis was found in maize crops, but it was captured also in the cemetery and on the river bank. It was also the dominant species in Asio otus pellets collected from the cemetery of Ozun (Lazăr, unpublished data). 
Family Muridae Iliger, 1811

14. Micromys minutus (Pallas, 1771) (Harvest Mouse) - was identified in pellets from Reci (Molnár 1980-1981). During the investigation, we captured one specimen in the cemetery, another in the arable land in a sugar beet crop in July 2006, and another specimen was observed in September 2011 in a potato crop.

15. Apodemus agrarius (Pallas, 1771) (Striped Field Mouse) - was mentioned from Reci (Molnár 1980-1981). In the habitats studied in Ozun, it was the dominant species throughout the study period, presenting the highest values of the capture and relative abundance indices. The dominance of $A$. agrarius was due to the high humidity in the area, caused by the presence of the Black River.

16. Apodemus flavicollis (Melchior, 1834) (Yellow-necked Field Mouse) - was the second-most abundant species in Ozun, and the only species captured in Dobârlău (one specimen) and Lisnău Vale.

17. Apodemus sylvaticus (Linnaeus, 1758) (Long-tailed Field Mouse) - due to the fact that the identification of species that belong to the Sylvaemus subgenus (A. sylvaticus and A. flavicollis) based on dentures is not always conclusive, these species are commonly considered together, as in the case of the forest near Reci (Molnár 1980-1981). However, Asio otus hunts mainly in open areas where A. sylvaticus occurs more frequently than A. flavicollis, which is a specific forest dweller. At Ozun we captured individuals belonging to the species A. sylvaticus in the cemetery and on the bank of the river, both in winter and spring.

18. Mus musculus Linaeus, 1758 (House Mouse) - was reported based on skeletal debris belonging to 29 individuals (0.98\%) in Asio otus pellets from Reci (Molnár 1980-1981). During the present study we captured one specimen in November 2005 in the Ozun cemetery and one specimen in a building in Lisnău Vale.

19. Rattus norvegicus (Berkenhout, 1769) (Brown Rat) - during the study one specimen was found dead in Ozun and several specimens were observed around some household annexes in Lisnău Vale.

Table 1 includes a synthesis of the localities where the small mammal species were mentioned in the literature and identified during the present study.

The results of the investigations on small mammal communities in the Ozun area are summarized in Table 2, which includes the number of specimens and the capture index in each habitat.

The dominant species in the investigation area was A. agrarius (72\%) (Fig. 1). Hygrophilous species, $A$. agrarius has optimal development conditions here because of the high humidity given by the proximity of the Black River, which borders the studied area to the east. A. flavicollis (15.5\%), although characteristic of forests, 
Table 1. Method used to identify the species in the study area (Ao - identified in Asio otus pellets, $\mathrm{O}$ - direct observation, $\mathrm{C}$ - captured with traps, Mc - specimens in museum collections, Os - signs of presence in the field)

\begin{tabular}{|c|c|c|c|}
\hline No. & Species & Literature & Present study \\
\hline 1. & Sorex araneus & Ao - Reci & $\mathrm{O}, \mathrm{C}-\mathrm{Ozun}$ \\
\hline 2. & Sorex minutus & Ao - Reci & C - Ozun \\
\hline 3. & Neomys fodiens & Ao - Reci & \\
\hline 4. & Neomys anomalus & Ao - Reci & \\
\hline 5. & Crocidura leucodon & Ao - Reci & \\
\hline 6. & Crocidura suaveolens & Ao - Reci & \\
\hline 7. & Talpa europaea & & O- Ozun \\
\hline 8. & Sciurus vulgaris & Mc - Covasna & O - Lisnău Vale \\
\hline 9. & Castor fiber & & Os - Ozun \\
\hline 10. & Cricetus cricetus & & O, Os - Ozun \\
\hline 11. & Myodes glareolus & Ao - Reci & C - Ozun \\
\hline 12. & Arvicola terrestris & Ao - Reci & O - Os - Lisnău Vale \\
\hline 13. & Microtus arvalis & Ao - Reci & Ao, C - Ozun \\
\hline 14. & Micromys minutus & Ao - Reci & C, $\mathrm{O}-$ Ozun \\
\hline 15. & Apodemus agrarius & Ao-Reci & C - Ozun \\
\hline 16. & Apodemus flavicollis & & C - Ozun, C- Lisnău Vale, C - Dobârlău \\
\hline 17. & Apodemus sylvaticus & & C- Ozun \\
\hline 18. & Mus musculus & Ao - Reci & C- Ozun, C - Lisnău Vale \\
\hline 19. & Ratus norvegicus & & O - Ozun,O - Lisnău Vale \\
\hline
\end{tabular}

is present in Ozun locality because of the woody vegetation in some of the investigated habitats. The third Apodemus species captured in the area, A. sylvaticus, was a constant presence, being captured in each habitat but with relatively low abundance (5.7\%). Among the shrews more abundant was S. araneus, which showed a low share in the community (1.6\%), although it was encountered in different habitats. The rest of the species had relatively low abundance, being captured in a small number.

Small mammals were more abundant on the river bank (Fig. 2). Here, although the capture effort was higher than in the other habitats, the capture index values were highest. A. agrarius showed similar values in the three habitats as a result of the uniform distribution of the species in the three habitats. A. flavicolis had the highest values of the capture index on the river bank, being absent from agricultural crops, highlighting the dependence of this species on woody vegetation.

The small mammal communities were clearly dominated by A. agrarius in all three habitats where more than one species was captured and it was the single species captured in the church courtyard. The species is favored by the humidity given 
Table 2. The total number of individuals captured in the five habitats investigated in Ozun locality. Trapping effort is expressed in number of trap-nights and capture index is expressed as number of individuals/100 trap-nights

\begin{tabular}{|c|c|c|c|c|}
\hline Habitat & Species & No. idividuals & Trapping effort & Capture index \\
\hline \multirow{7}{*}{ Cemetery } & A. flavicollis & 4 & 555 & 0.72 \\
\hline & A. agrarius & 47 & 555 & 8.46 \\
\hline & S. minutus & 1 & 555 & 0.18 \\
\hline & A. sylvaticus & 6 & 555 & 1.08 \\
\hline & M.arvalis & 1 & 555 & 0.18 \\
\hline & M. msculus & 1 & 555 & 0.18 \\
\hline & M. minutus & 1 & 555 & 0.18 \\
\hline \multirow{6}{*}{ River bank } & M. glareolus & 1 & 704 & 0.14 \\
\hline & A. flavicollis & 26 & 704 & 3.69 \\
\hline & S. araneus & 2 & 704 & 0.28 \\
\hline & A. agrarius & 66 & 704 & 9.38 \\
\hline & A. sylvaticus & 1 & 704 & 0.14 \\
\hline & M.arvalis & 1 & 704 & 0.14 \\
\hline \multirow{4}{*}{ Agricultural crops } & A. agrarius & 21 & 240 & 8.73 \\
\hline & A. sylvaticus & 4 & 240 & 1.66 \\
\hline & M. arvalis & 3 & 240 & 1.25 \\
\hline & M. minutus & 1 & 240 & 0.42 \\
\hline Permanent crops & - & - & 106 & 0.00 \\
\hline Church courtyard & A. agrarius & 5 & 29 & 17.24 \\
\hline
\end{tabular}

by the proximity of the Black River and by the presence of agricultural crops in the immediate vicinity of the studied habitats.

The small mammal community in the cemetery was the most diverse, here being captured seven of the nine species identified in the Ozun locality. This high diversity is primarily due to the stability of the habitat, which is not affected by the major changes occurring in the other two analyzed habitats (i.e. fluctuations of the water level and periodic floods on the river bank, or periodical agricultural works in agricultural crops). A. flavicollis had a relatively low share (6.55\%), being present in this habitat because of Syringa vulgaris. However, the absence of trees limits the abundance of this species in the cemetery.

The small mammal community on the Black River bank was poorer, dominated also by $A$. agrarius. Although on the riverbank moisture was highest among the surveyed habitats, the relative abundance of $A$. agrarius was lower compared to the cemetery and the crops A. flavicollis recorded the maximum value of the capture index in this habitat. Myodes glareolus, represented by one captured specimen. 


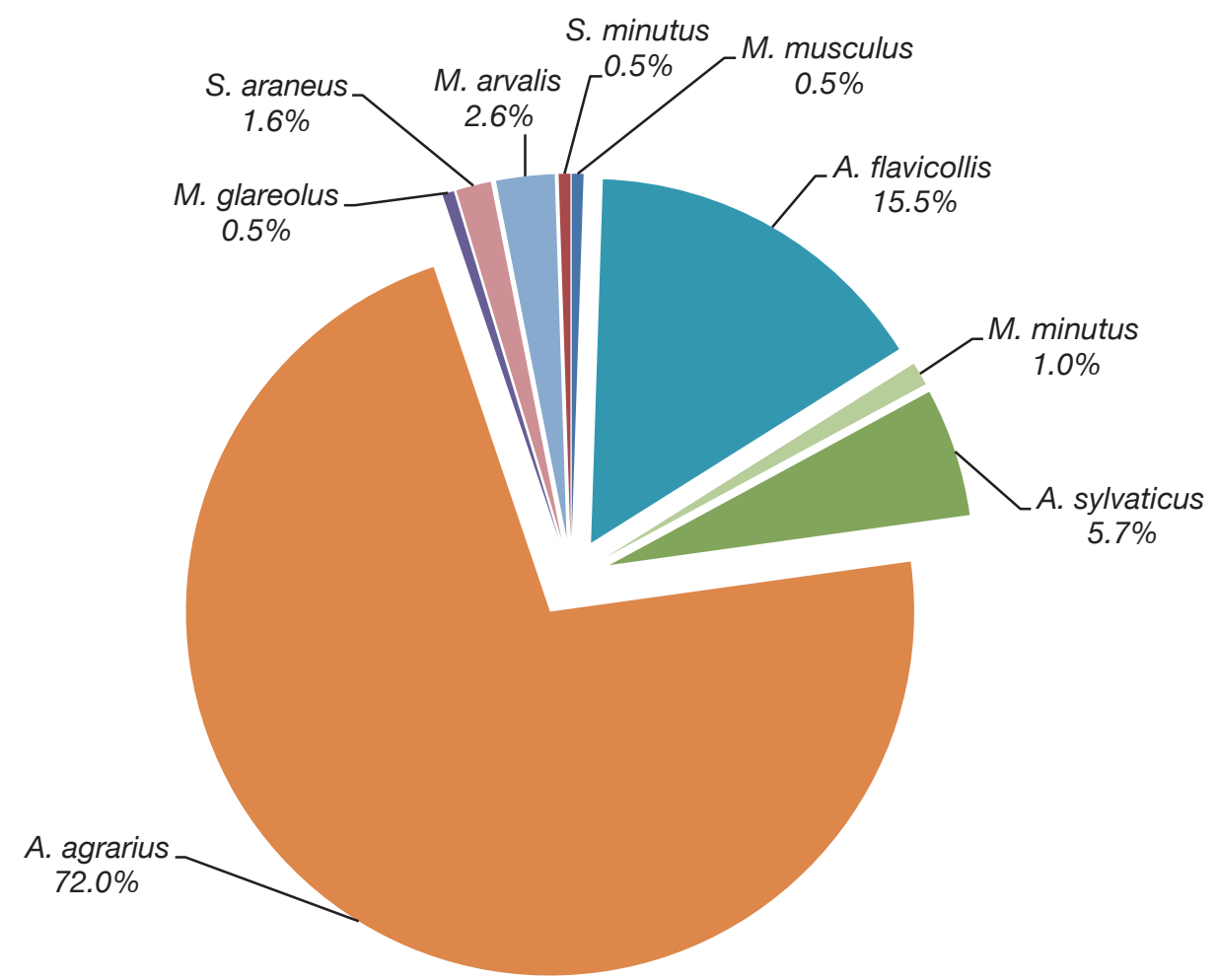

Figure 1. Relative abundance of small mammal species captured between November 2005 and June 2012 in Ozun locality.

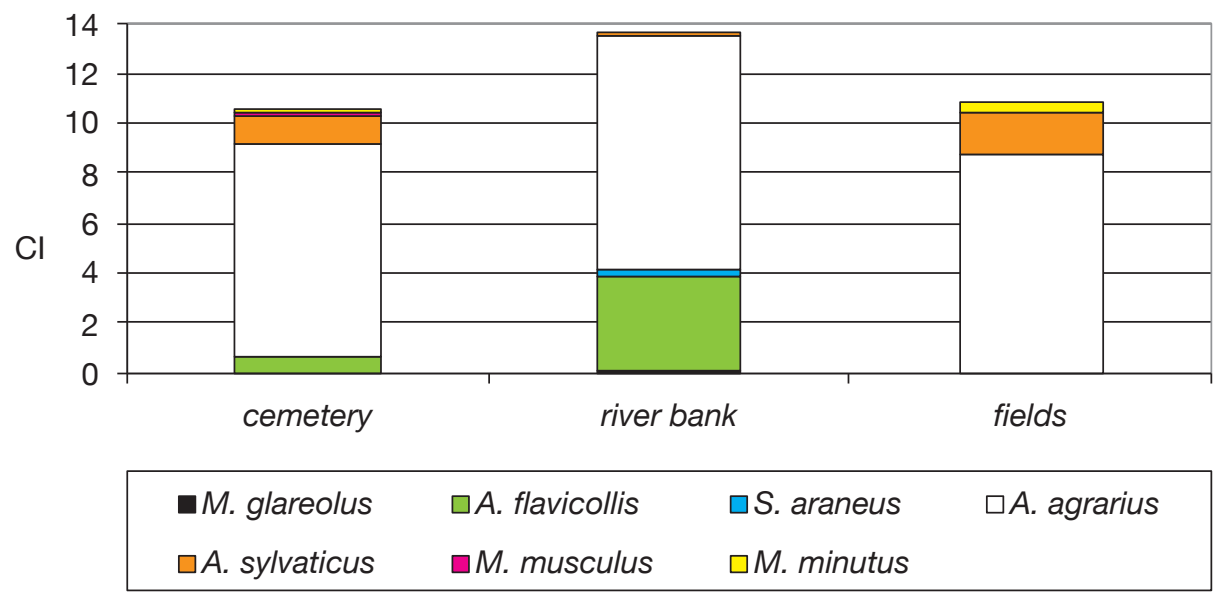

Figure 2. The total capture index in the three habitats investigated in Ozun station locality where it was captured more than one species 
The agricultural land was the poorest habitat in species (four species) because of the high instability due to the periodic works (i.e. tillage, sowing, harvesting). It was also dominated by $A$. agrarius followed by Microtus arvalis. Although in the agricultural land the common vole had the highest relative abundance compared to the other two studied habitats, its value was low (10.34\%). This may be due, on the one hand, to the higher competitiveness of A. agrarius, when it is in the optimal habitat, and on the other hand to a possible reluctance of $M$. arvalis to visit the traps. Similar situations have already been encountered in Lisa and Breaza stations in Făgăraș Piedmont (Lazăr et al. 2012). Other species have low relative abundances, being captured only occasionally.

At Lisnău Vale we captured six specimens of A. flavicollis in the wooded pasture. No capture was recorded in the traps installed in the pasture. This result highlights the low capacity of open habitats to shelter small mammals in the cold season. This was also observed in the Ozun locality, where during winter abundance of small mammals was much lower than in the other habitats.

\section{Conclusions}

During the field investigations carried out between 2005 and 2012 in the Lower Black River Basin, we captured nine species of small mammals, of which two shrews and seven rodents, and four other species were reported by other methods. In the surveyed area, the small mammal community was dominated by Apodemus agrarius, and as the density of woody vegetation within the studied habitats increased, the relative abundance of Apodemus flavicollis also increased. Open habitats have a lower capacity to shelter small mammals, especially during the cold season, a phenomenon that was noticeable both in Ozun and Lisnău Vale localities. Stable habitats have a greater ability to shelter richer and more diverse communities of small mammals.

\section{References}

Aulagnier S, Haffner P, Mitchell-Jones AJ, Moutou F, Zima J (2009) Mammals of Europe, North Africa and the Middle East. AandC Black Publishers, London, 272 pp.

Bielz EA (1888) Die Fauna der Wirbeltiere Siebenbürgens nach ihrem gegenwartigen Stande [The fauna of the vertebrates of Transylvania according to their present state]. Verhandlungen und Mitteilungen des Siebenbürgischen Vereins für Naturwissenschaften zu Hermanstadt 38: 15-36. [in German]

Görner M, Hackenthal H (1988) Säugetiere Europas [Mammals of Europe]. Neumann Verlag, Leipzig, 367 pp. [in German] 
Ionescu G, Ionescu O (2000) Reintroducerea castorului în bazinul Oltului [Reintroduction of the beaver in the Olt basin]. Revista de Silvicultură, Braşov 5(1-2): 74-76 [in Romanian]

Lazăr A, Lazăr C, Benedek AM, Suvăială AM (2012) Terrestrial Small Mammal Communities from the Făgăraș Piedmont (Romania). Travaux du Muséum National d'Histoire Naturelle "Grigore Antipa" 55(2): 291-304.

Molnár L (1980-1981) Adatok az erdei fülesbagoly (Asio otus L.) táplákozásához Kovászna megyében köpetvizsgálattok alapján [Data on nutrition of Asio otus L. in Covasna County, based on pellets]. Aluta. Studii și Comunicări. Muzeul Județean Covasna, Sfîntu Gheorghe 12-13: 415-425. [in Hungarian]

Murariu D (2000) Insectivora. Fauna României, XVI (Mammalia) [Insectivora. Romanian Fauna, XVI (Mammalia)], 1, 142 pp. [in Romanian]

Popescu A, Murariu D (2001) Rodentia. Fauna României, XVI (Mammalia) [Rodentia. Romanian Fauna, XVI (Mammalia)], 2, 214 pp. [in Romanian]

Puceck Z (Ed) (1981) Keys to Vertebrates of Poland - Mammals. Polish Scientific Publishers, Warszawa, $367 \mathrm{pp}$.

Sîrbu I (2009) Bazele modelării proceselor și sistemelor ecologice [Basis of modeling processes and ecological systems]. Editura Universității Lucian Blaga din Sibiu, 174 pp. [in Romanian]

Sîrbu I, Benedek AM (2012) Ecologie practică. Ediția a 3-a [Practical Ecology. Third Edition]. Editura Universității Lucian Blaga din Sibiu, 292 pp. [in Romanian]

Stanca C, Ráduly G (1980) Județul Covasna, Monografie [Monograph of Covasna county]. Editura Sport Turism București, 254 pp. [in Romanian]

Wilson DE, Reeder DM (Eds) (2005) Mammal Species of the World. A Taxonomic and Geographic Reference (3rd edition), Johns Hopkins University Press, 142 pp. 